\title{
The Distributed Generation as an Important Contribution to Energy Development in Angola and Other Developing African Countries
}

\author{
Joaquim Moreira Lima ${ }^{1,2}$, José Barata ${ }^{1}$, Miguel Fernandez ${ }^{3}$, and Angel Montiel ${ }^{2}$ \\ ${ }^{1}$ Universidade Nova de Lisboa / UNINOVA, Quinta da Torre, 2829-516 Caparica, Portugal \\ jab@uninova.pt \\ ${ }^{2}$ INTEL Lda, Luanda, Angola \\ jomoreli@netcabo.pt \\ ${ }^{3}$ CIPEL, Havana, Cuba \\ mcastro@electrica.cujae.edu.cu
}

\begin{abstract}
Distributed generation (DG) is related to the use of small or medium size generating units close to the load centers. DG has great benefits for application in places distant from the major centers of production where the population needs a reliable and cheap supply of electric power. This is the case of Angola and the majority of other African countries. This paper discusses the potential that distributed generation may have in these countries highlighting four crucial aspects: the utilization of a realistic and simple optimal allocation method, the consideration of intentional islanding mode of operation, the utilization of all the existing sources of energy in the region, specially the renewable ones, and the demand side management of energy through the application of smart metering and communication techniques.
\end{abstract}

Keywords: Distributed Generation, Intentional Islanding, Energy Efficiency, Demand Side Management, Smart Metering.

\section{Introduction}

Although there is a lot of definitions of distributed generation in the technical literature [1-5], we are going to present our own definition, considering that, on one hand, nowadays there are a large number of technologies to be incorporated into this concept and on the other hand, the increasing incorporation of artificial intelligence and the new technologies of computing and communications. Facing these facts, it is proposed the following definition of distributed generation:

Distributed generation consists of the supply and storage sources of electrical and thermal energy located in the distribution network, close to the points of consumption, together with the possibility of forming intelligent and highly automated networks, able to control and integrate the operation of the different supply and storage sources with the active participation of consumers in both the purchase and sale of energy, as well as in their more economical and environmental use. 
The benefits of employing distribution generation in existing distributed networks have economical, technical and environmental implications and they are interrelated. In spite of the fact that in the literature many advantages for the distributed generation are exposed, it is possible to reduce them to four main aspects that comprise in one way or another, the rest of the advantages that can be argued [6-8]. These four aspects are: are increased reliability, line loss reduction, voltage profile improvement and environmental impact reduction.

This paper seeks to explain the most important aspects that must be taken into account to justify the introduction in Angola a mix of this concept and the challenges that the application of this generation paradigm might imply.

\section{Relationship to Collective Awareness Systems}

The current challenges faced by the Energy sector involve complex interactions between humans and machines with intelligent decision making or behavior. More and more intelligent energy based devices are being applied to create intelligent and adaptive systems in the production, transport, and distribution of electrical energy. The grid is becoming more intelligent (SMART GRID) both at device level and at system level. It is important to understand that the SMART GRID is above all a distributed system composed of intelligent nodes (machines and humans) that regulates and control de demand and supply in a sustainable way.

The SMART GRID and distributed energy in particular are completely dependent on cyberphysical systems that are at its kernel. Considering the different actors involved and interacting with the grid what is available is a complex system in which different services are being used and created in a dynamic way to accommodate the different actors. In particular it is important to stress the importance of customers that more and more interact with producers and suppliers. The internet of things is therefore a concept well in line with this new world of energy.

It is clear that the emerging energy systems (SMART GRID) are socio-technical systems capable of harnessing collective intelligence for promoting innovation and taking better, informed and sustainability-aware decisions, Therefore, the development of Collective Awareness Systems will have a strong and beneficial impact on the creation of effective and sustainable energy systems.

\section{Motivation}

Angola is a country where almost all energy resources known all over the world can be found. The energy potential from national rivers is enormous and it is one of the major oil producers in Africa. This has resulted on a energy generation planning based on the intensive exploitation of these energy resources and in the construction of big and expensive infrastructures to transport the electric power to very distant places [9].

It was only in the last few years that a strategic plan was developed to include in the country's energy mix the varied and abundant sources of renewable energy. 
However, it was not carried out large-scale plans to introduce the energy efficiency and power management on the demand side.

Accordingly, our proposal to improve the reliability of the Angolan electric system is based on the hypothesis that it is possible to consider the comprehensive use of distributed generation in Angola taking into account four important factors: the optimal allocation of the units of distributed generation, the possibility of operating on intentional island mode, the use of all available energy resources and the active participation of the demand side utilizing smart grids and smart metering

\section{Optimal Allocation of Distributed Generation}

From the very beginning of the introduction of the generation in the distribution networks this has been one of the most important problems faced by specialists and researchers due to the fact that an incorrect planning of these units can lead to an increase in the cost of both investment and exploitation thus losing one of the main advantages of this type of generation.

In the early years of this century there were several papers about the location and sizing of the units taking into account only the decrease of losses in the network [1012]. These studies consider also that there is a source of generation in each node and limited load scenarios. Also at this time there were several important researchers that attempted to quantify the benefits from the introduction of distributed generation with the goal of providing tools for the economic feasibility studies of this type of generation. Among these works is particularly important the paper submitted by Chiradeja Ramakumar [6].

A large number of methods for the optimal location and size of the GD based on the use of genetic algorithms or fuzzy logic were proposed [13-16]. It also introduced new variants of evolutionary algorithms such as the so-called Particle Swarm Optimization (PSO), Honey Bee Mating (HBM), Tabu Search (TS), Simulated Annealing (SA), Differential Evolution (DE) and Cokoo Search (CS). All of them are heuristic or meta-heuristic methods based on iterative procedures and considering different objective functions [17-24]. Among the major aspects to be considered in the proposed objective functions are the losses in the network, the voltage profile, the greenhouse gas emissions, the savings in the costs of expansion of the transmission system and the reliability.

There has been a great contrast between the level of development achieved by the theoretical and academic studies of optimal location of distributed generation units and, in some cases, a lack of will and rejection of the utilities to its introduction due to the fact that these studies have not consider the uncertainties and risk factors present at all times. From the point of view of real-world application, geographical, climatic and social factors could change completely the results obtained by means of sophisticated methods purely mathematical since they have not been taken into account. It is also true that the advantages of one method over another are mainly based on an easier consideration of the objective functions or in the saving of computing time. 
Concerning the optimal localization studies, the fact of variability and the forecasting difficult to deliver energy and the influence of these factors both the size and the location of the units of distributed generation have been considered by some authors only $[25,26]$.

According to these facts, the proposed method of optimal location will take some aspects into consideration: A mathematical method that could simplifies the development and implementation of the proposed software, the reliability of the whole system, the transmission losses, the voltage profiles at the more frequent load scenarios, also as a priority, the geographic, climatic and social more important factors as well as the presence of renewable energy sources and their variability as part of the possible scenarios.

This well in line with the research question of this $\mathrm{PhD}$ work is which computational methods and tools should be used for the optimal location of distributed generation units in the context of under developing countries and considering environmental factors.

\section{$5 \quad$ Islanding as a Normal Mode of Operation of Distributed Generation Networks}

A set of distributed generation units having different technologies are usually connected to the Utility Network through a common point of connection (CPC) where there is a coupling transformer.

It can happen that, mainly due to faults in the utility or distributed generation network, the CPC is disconnected and form an island or isolated system. The rules of connection of the distributed generation to the network disconnect immediately all the distributed generation units by interrupting the service users. But more recently has been questioned this policy due to the economic losses that brings to the users the energy not supplied caused by these blackouts.

It has been proposed to continue operating the distribution network in isolation mode, diminishing the quality of the energy parameters but guaranteeing the supply to users. In this way, an increased service quality is achieved. This policy has almost always been rejected by the large utilities but has been seen in recent years a greater flexibility in this regards.

The most important challenges in adopting a policy of intentional islanding operation are the sharing of the power load, which could include load shedding, the frequency and voltage control and the subsequent synchronization of the island with the network [27].

The solution of these problems, even without reducing the quality of service, is nowadays a reality due to the application of the most modern techniques of computing and communications and the introduction of new concepts and techniques of operation of networks such as the smart grids and metering and the virtual power plants [28-30].

We propose that, as a part of the incorporation of distributed generation to the Angolan mix, the operation on intentional islanding mode should be considered. 


\section{Sustainability of the Projects of Distributed Generation}

Sustainability means an equitable distribution of limited resources and opportunities in the context of the economy, the society, and the environment seeking the wellbeing of everyone, now and in the future [34, 35]. A sustainable energy solution generates enough energy for all at a reasonable price in a clean, safe and reliable way.

In regard to the technologies used, machines such as internal combustion engines or Diesel, gas turbines, microturbines, fuel cells, biomass and renewable energies extracting the energy of the sun and wind as the photovoltaic solar energy and wind power, are recognized as sources of energy utilized in distribution generation [36].

Within these technologies, are the renewable energy, solar and wind, which have the biggest sustainability and greater benefits from an environmental point of view but have the disadvantage that depend on climatic factors that vary according to the time of the day and the season. On account of that, they are difficult to predict and, therefore, are not "dispatchable". In spite of that, its use and expanding potential are increasing [37, 38].

A few years ago, while recognizing the great potential of renewable energy sources as part of distributed generation in the more rational use of electric energy, it was a great concern that precisely this dispersal and not "dispatchable" characteristic of this type of sources, could give rise to a liability diluted among the large utilities, the costumers and local producers [35].

In the last years this situation has been changing mainly motivated by the development of new organization concepts of the electrical networks such as the microgrid and the virtual power plants, already mentioned, and also by the increase in international pressure for searching energy productions solutions more efficient, clean and reliable [26, 37].

Consequently we propose that clean and renewable energies available in Angola must be effectively used.

\section{$7 \quad$ Demand Side Management and Smart Metering}

The participation of the consumer and the local producer of energy in the implementation of energy efficiency policy is so-called Demand Side Management. Due to the lack of awareness of the Angolan population and some authorities concerning the necessity of saving electrical energy and use it more rationally this DSM concept is necessary to evaluate at the proposal to solve the Angolan electric system develop.

This participation is proposed through several methods such as financial incentives and education. The goal of demand side management is to encourage the consumer to use less energy during peak hours or to translate the energy utilization to off peak hours such as nighttime and weekends. Peak demand management does not necessarily decrease total energy consumption but could be expected to reduce the need for investment in networks components and the size of distributed generation energy sources. 
There are three models for implantation the Demand Side Management:

1. Energy efficiency. Using less power to perform the same tasks.

2. Demand Response. Any preventive method to reduce, flatten or shift peak demand that includes all intentional modifications to consumptions patterns of electricity. It is related to a wide range of actions which can be taken at the customer side of the electricity meter in response to particular condition of the electricity meter (peak period, network congestion, high prices) [39].

3. Dynamic Demand. Advance or delay appliance operating cycle by a few seconds to increase the Diversity Factor of the whole load. The concept is that by monitoring the power factor of the power grid, as well as their own control parameters, individual, intermittent loads would switch on or off at optimal moments to balance the overall system load with generation, reducing critical power mismatches [40].

The successful implementation of the demand side management would be impossible without the application of the so-called Smart Metering based on the smart meter.

A smart meter is usually an electrical meter that records consumption of electric energy in intervals of an hour or less and communicates that information at least daily back to the utility for monitoring and billing purposes. Smart meters enable two-way communication between the meter and the central system. The possibility of this twoway communication of smart metering makes its utilization mandatory in our proposal.

\section{Conclusions}

We conclude that, to solve the lack of reliability of the electrical system in Angola it is mandatory to apply a new concept of distributed generation who bears in mind the needs of the different regions of the country, the available resources and the application of the last advances in the information and communication technologies, emphasizing the following aspects:

- The optimal allocation of the units of distributed generation taking into account the decrease of power losses, the improvement of the voltage profile, the characteristics of the demand and the possible variability of the sustainable available sources of energy as well as utilizing an adequate and simple software. This the main focus of this $\mathrm{PhD}$ research.

- To consider, as a part of the proposal, the possibility and necessity to create intentional islands that increase the availability of the electric power to the consumers.

- To utilize all the energy resources available in the region in a sustainable way and considering the possible environmental aspects.

- To apply the demand side management of the energy consumed and produced utilizing the smart metering and communication possibilities.

Acknowledgments. This work was partially supported by CTS multi-annual funding, through the PIDDAC Program funds. 


\section{References}

1. Ackermann, T., Andersson, G., Soder, L.: Distributed generation: a definition. Electric Power Systems Research 57(3), 195-204 (2001)

2. Pepermans, G., et al.: Distributed generation: definition, benefits and issues. Energy Policy 33(6), 787-798 (2005)

3. Bessmertnykh, A., Zaichenko, V.: Development of distributed power generation. Herald of the Russian Academy of Sciences 82(5), 398-402 (2012)

4. Lopes, J., et al.: Integrating distributed generation into electric power systems: A review of drivers, challenges and opportunities. Electric Power Systems Research 77(9), 1189-1203 (2007)

5. González-Longatt, F., Fortoul, C.: Review of the Distributed Generation Concept: Attempt of Unification. In: ICREPQ 2005 - International Conference on Renewable Energies and Power Quality, Zaragoza - Spain (2005)

6. Chiradeja, P., Ramakumar, R.: An approach to quantify the technical benefits of distributed generation. IEEE Transactions on Energy Conversion 19(4), 764-773 (2004)

7. Poullikkas, A.: Implementation of distributed generation technologies in isolated power systems. Renewable \& Sustainable Energy Reviews 11(1), 30-56 (2007)

8. Castro, M.: Distributed Generation and Renewable Energy: The Cuban Experience. In: ACEEW 2013 - Angolan Conference on Energy Engineering and Water, Luanda - Angola (2013)

9. MINEA, Ministry of Energy and Water of Angola - Plano de Desenvolvimento Energético (Energy development Plan). MINEA: Luanda - Angola (2012)

10. Hadjsaid, N., Canard, J., Dumas, F.: Dispersed generation impact on distribution networks. IEEE Computer Applications in Power 12(2), 22-28 (1999)

11. Wang, C., Nehrir, M.: Analytical approaches for optimal placement of distributed generation sources in power systems. IEEE Transactions on Power Systems 19(4), 2068-2076 (2004)

12. Griffin, T., et al.: Placement of Dispersed Generations Systems for Reduced Losses. In: 33rd Hawaii International Conference on System Sciences. IEEE Xplore (2000)

13. Celli, G., et al.: A multiobjective evolutionary algorithm for the sizing and siting of distributed generation. IEEE Transactions on Power Systems 20(2), 750-757 (2005)

14. Borges, C., Falcao, D.: Optimal distributed generation allocation for reliability, losses, and voltage improvement. International Journal of Electrical Power \& Energy Systems 28(6), 413-420 (2006)

15. Cano, E.B.: Utilizing Fuzzy Optimization for Distributed Generation Allocation. In: TENCON 2007 - 2007 IEEE Region 10 Conference. IEEE Xplore (2007)

16. Varikuti, R., Reddy, M.D.: Optimal Placement of DG Units Using Fuzzy and Real Coded Genetic Algortihm. Journal of Theoretical and Applied Information Technology 7(2), 145-151 (2009)

17. Abdi, S., Afshar, K.: Application of IPSO-Monte Carlo for optimal distributed generation allocation and sizing. International Journal of Electrical Power \& Energy Systems 44(1), 786-797 (2013)

18. Doagou-Mojarrad, H., et al.: Optimal placement and sizing of DG (distributed generation) units in distribution networks by novel hybrid evolutionary algorithm. Energy 54, 129-138 (2013)

19. Nekooei, K., et al.: An Improved Multi-Objective Harmony Search for Optimal Placement of DGs in Distribution Systems. IEEE Transactions on Smart Grid 4(1), 557-567 (2013) 
20. Viral, R., Khatod, D.: Optimal planning of distributed generation systems in distribution system: A review. Renewable \& Sustainable Energy Reviews 16(7), 5146-5165 (2012)

21. Porkar, S., et al.: Optimal allocation of distributed generation using a two-stage multiobjective mixed-integer-nonlinear programming. European Transactions on Electrical Power 21(1), 1072-1087 (2011)

22. Moradi, M., Abedini, M.: A combination of genetic algorithm and particle swarm optimization for optimal DG location and sizing in distribution systems. International Journal of Electrical Power \& Energy Systems 34(1), 66-74 (2012)

23. Moravej, Z., Akhlaghi, A.: A novel approach based on cuckoo search for DG allocation in distribution network. International Journal of Electrical Power \& Energy Systems 44(1), 672-679 (2013)

24. El-Zonkoly, A.: Optimal placement of multi-distributed generation units including different load models using particle swarm optimisation. IET Generation Transmission \& Distribution 5(7), 760-771 (2011)

25. Niknam, T., et al.: A modified honey bee mating optimization algorithm for multiobjective placement of renewable energy resources. Applied Energy 88(12), 4817-4830 (2011)

26. Atwa, Y., et al.: Optimal Renewable Resources Mix for Distribution System Energy Loss Minimization. IEEE Transactions on Power Systems 25(1), 360-370 (2010)

27. Gomez, J., Morcos, M.: Letter to the Editor: On Islanding Operation in Systems with Distributed Generation. Electric Power Components and Systems 37(2), 234-237 (2009)

28. Dash, P., Padhee, M., Barik, S.: Estimation of power quality indices in distributed generation systems during power islanding conditions. International Journal of Electrical Power \& Energy Systems 36(1), 18-30 (2012)

29. Best, R., et al.: Synchronous islanded operation of a diesel generator. IEEE Transactions on Power Systems 22(4), 2170-2176 (2007)

30. Wissner, M.: The Smart Grid - A saucerful of secrets? Applied Energy 88(7), 2509-2518 (2011)

31. Kundar, P., et al.: Definition and classification of power system stability (vol. 18, pg 1387, 2004). IEEE Transactions on Power Systems 19(4), 2124 (2004)

32. Kundur, P., et al.: Definition and classification of power system stability. IEEE Transactions on Power Systems 19(3), 1387-1401 (2004)

33. Xyngi, I., et al.: Transient Stability Analysis of a Distribution Network With Distributed Generators. IEEE Transactions on Power Systems 24(2), 1102-1104 (2009)

34. Alanne, K., Saari, A.: Distributed energy generation and sustainable development. Renewable \& Sustainable Energy Reviews 10(6), 539-558 (2006)

35. Bugaje, I.: Renewable energy for sustainable development in Africa: a review. Renewable \& Sustainable Energy Reviews 10(6), 603-612 (2006)

36. Huang, J., Jiang, C., Xu, R.: A review on distributed energy resources and MicroGrid. Renewable \& Sustainable Energy Reviews 12(9), 2472-2483 (2008)

37. Tan, W., et al.: Optimal distributed renewable generation planning: A review of different approaches. Renewable \& Sustainable Energy Reviews 18, 626-645 (2013)

38. Loughran, D., Kulick, J.: Demand-side management and energy efficiency in the United States. Energy Journal 25(1), 19-43 (2004)

39. Albadi, M., El-Saadany, E.: A summary of demand response in electricity markets. Electric Power Systems Research 78(11), 1989-1996 (2008)

40. Torriti, J., Hassan, M., Leach, M.: Demand response experience in Europe: Policies, programmes and implementation. Energy 35(4), 1575-1583 (2010) 